\title{
The oncogenic role of Wnt10a in colorectal cancer through activation of canonical Wnt/ $\beta$-catenin signaling
}

\author{
JINLONG LI $^{1}$, ZHAOLI ZHANG ${ }^{2}$, LIXUE WANG ${ }^{3}$ and YONGCHEN ZHANG ${ }^{1}$ \\ Departments of ${ }^{1}$ Laboratory Medicine, ${ }^{2}$ Pharmacy and ${ }^{3}$ Oncology, The Second Affiliated Hospital \\ of Southeast University, Nanjing, Jiangsu 210003, P.R. China
}

Received May 9, 2018; Accepted January 3, 2019

DOI: $10.3892 / \mathrm{ol} .2019 .10035$

\begin{abstract}
Colorectal cancer (CRC) is one of the major causes of cancer-associated mortality worldwide. Wnt family member 10A (Wnt10a) is an oncogene associated with the carcinogenesis and progression of renal cell carcinoma, and is strongly expressed in the CRC cell line SW480. However, the role of Wnt10a in CRC has been rarely reported. In the present study, the expression levels of Wnt10a were higher in 40 tumor tissues compared with in paired control tissues, as determined by RT-qPCR method. In addition, the clinic opathological association analysis indicated that Wnt10a expression was associated with tumor stage $(\mathrm{T} 3+\mathrm{T} 4, \mathrm{P}=0.015)$. Furthermore, Wnt10a was highly expressed in the SW480, SW620 and HCT116 cell lines. In order to explore the role of Wnt10a in CRC, Wnt10a expression was knocked down by siRNA technology in HCT116 cell line. Cell proliferation was significantly inhibited by $55 \%$ in CCK-8 assay following Wnt10a knockdown and cell migration rate was decreased by $50 \%$ in Transwell assay. In addition, western blot analysis demonstrated that Wnt10a knockdown decreased the expression levels of $\beta$-catenin, cyclin D1, lymphoid enhancer-binding factor 1 and protein kinase $\mathrm{B}$, which was consistent with results obtained with the Wnt/ $\beta$-catenin specific inhibitor LGK-974. It was thus suggested that Wnt10a downregulation inactivated the Wnt/ $\beta$-catenin signaling pathway in HCT116 cells. In conclusion, the present study demonstrated that Wnt10a may have an oncogenic role during carcinogenesis of CRC through activation of $\mathrm{Wnt} / \beta$-catenin signaling.
\end{abstract}

\section{Introduction}

Colorectal cancer (CRC) is the third most common and third most lethal type of cancer in men and women in the United

Correspondence to: Professor Yongchen Zhang, Department of Laboratory Medicine, The Second Affiliated Hospital of Southeast University, 1-1 Zhongfu Road, Nanjing, Jiangsu 210003, P.R. China E-mail: tangb_1210@126.com

Key words: Wnt10a, Wnt/ $\beta$-catenin signaling, proliferation, migration, siRNA
States (1). The 5-year survival rate for patients with metastatic CRC is $<15 \%$ (2). The main therapeutic options for CRC include traditional methods, such as surgery, chemotherapy, and possibly radiation if the tumor is well localized (2-6). In addition, genetic heterogeneity of $\mathrm{CRC}$ is associated with patient prognosis (7). It is therefore crucial to determine the underlying mechanism of CRC in order to develop novel therapeutic drugs for its treatment.

Genes from the WNT family are known to serve critical roles during embryonic development and tissue homeostasis (8-10). The Wnt family is comprised of 19 members that can be categorized into two classes based on $\beta$-catenin involvement: The canonical pathway or $\beta$-catenin-dependent pathway, and the non-canonical pathway or $\beta$-catenin-independent pathway (8). In the canonical pathway, Wnt ligand binds to Frizzled receptor and inhibits the activity of glycogen synthase kinase-3 $\beta$ (GSK3 $\beta$ ), which leads to aberrant accumulation of $\beta$-catenin in the cytoplasm followed by translocation to the nucleus. In the nucleus, $\beta$-catenin then binds to T-cell factor (TCF)/lymphoid enhancer-binding factor (LEF) and activates the transcription of downstream target genes. In addition, GSK $3 \beta$ can phosphorylate $\beta$-catenin, inducing ubiquitination and proteosomal degradation when the appropriate Wnt ligand is lacking $(8,11)$.

The aberrant activation of Wnt/ $\beta$-catenin signaling has been implicated in various types of tumor $(8,12,13)$. Furthermore, mutated $\beta$-catenin is an important mechanism involved in the carcinogenesis of various types of tumor (14). However, other mechanisms disrupt the growth and/or invasion of tumors, including polymorphisms and differential expression of Wnt protein. For example, overexpression of Wnt family member 1 (Wnt1) is associated with advanced metastasis in patients with non-small cell lung cancer, and promotes migration and invasion of H1299 cells (15). Furthermore, Wnt7a is abundantly expressed in the epithelium of serous ovarian cancer, and promotes the tumor growth and progression of ovarian cancer via the $\mathrm{Wnt} / \beta$-catenin signaling pathway (16). In addition, the upregulation of Wnt5a is associated with poor prognosis in patients with CRC, and Wnt5a knockdown in the SW480 cell line inhibits migration and invasion of SW480 cells (17). Polymorphisms in Wnt6 and Wnt10a genes increase the risk of colorectal adenoma (18), and Wnt10a is highly expressed in renal cell carcinoma (RCC) tissue, thus serving an oncogenic role during carcinogenesis of RCC (19). Wnt10a has also been reported to be strongly expressed in SW480 cells $(20,21)$. 
However, to the best of our knowledge, there is currently no study available on the function of Wnt10a and its underlying mechanism in the carcinogenesis and progression of CRC.

In the present study, Wnt10a was revealed to be overexpressed in CRC tissues, and its expression was associated with the survival rate of patients with CRC. In addition, a functional assay demonstrated that Wnt10a may promote HCT116 cell proliferation through activation of the Wnt/ $\beta$-catenin signaling pathway. The in vivo data further supported the oncogenic role of Wnt10a in CRC. In conclusion, results from the present study suggested that Wnt10a may be a tumor-promoting gene in CRC and may be a novel target for the treatment of patients with CRC.

\section{Materials and methods}

Cell lines and tissue samples. The human CRC cell lines HCT116, SW480 and SW620 were purchased from the Cell Bank Type Culture Collection of Chinese Academy of Sciences (Shanghai, China). HCT116 cells were maintained in Dulbecco's modified Eagle's medium (DMEM; Gibco; Thermo Fisher Scientific, Inc., Waltham, MA, USA) supplemented with $10 \%$ fetal bovine serum (FBS; Gibco; Thermo Fisher Scientific, Inc.) and antibiotics (100 U/ml penicillin and $100 \mu \mathrm{g} / \mathrm{ml}$ streptomycin). SW480 and SW620 cells were cultured in L-15 medium (Gibco; Thermo Fisher Scientific, Inc.) containing $10 \% \mathrm{FBS}$. All cells were cultured at $37^{\circ} \mathrm{C}$ in a humidified incubator containing $5 \% \mathrm{CO}_{2}$.

A total of 40 patients with primary colon adenocarcinoma were selected between June, 2016 and December, 2017 at the Department of Oncology of The First Affiliated Hospital of Nanjing Medical University (Nanjing, China). The development and pathogenic progression of CRC were diagnosed and classified by histopathological examination according to the study by Cunninghan et al (22). Tissues $5 \mathrm{~cm}$ distant from the resection margin were harvested and defined as paratumoral control tissues. Written informed consent was obtained from individual subjects. The experimental protocols were approved by the Ethics Committee of The Second Affiliated Hospital of Southeast University (Nanjing, China). All experiments complied with current national laws.

Reverse transcription-quantitative polymerase chain reaction $(R T-q P C R)$. Total RNA from colorectal and paratumoral tissues or cells was extracted using TRIzol ${ }^{\circledR}$ reagent (Invitrogen; Thermo Fisher Scientific, Inc.). The cDNA was prepared from $2 \mu \mathrm{g}$ total RNA with a Reverse Transcription System (Promega Corporation, Madison, WI, USA), according to the manufacturer's protocol. A volume of $1 \mu \mathrm{l}$ cDNA was then used as a template for RT-qPCR with the standard SYBR Green RT-PCR kit (Takara Bio. Inc., Otsu, Japan) to evaluate the mRNA expression levels of Wnt10a and GAPDH (internal control). Primer sequences of Wnt10a and GAPDH are presented in Table I. RT-qPCR was performed on an ABI 7500 real-time PCR system (Applied Biosystems; Thermo Fisher Scientific, Inc.). Data were analyzed with the ABI 7500 V2.0.6 software and results were presented as relative quantification normalized to GAPDH. Analyses were based on the calculations of $2^{-\Delta \mathrm{Cq}}$ where $\Delta \mathrm{Cq}=\mathrm{Cq}$ (Target)- $\mathrm{Cq}$ (Reference). Fold change was calculated using the $2^{-\Delta \Delta C q}$ method (23). All samples were examined in triplicate. The RT-qPCR procedure was performed as follows: Pre-denaturation at $95^{\circ} \mathrm{C}$ for $1 \mathrm{~min}$, followed by 45 cycles of denaturation at $95^{\circ} \mathrm{C}$ for $15 \mathrm{sec}$, and annealing and extension at $60^{\circ} \mathrm{C}$ for $30 \mathrm{sec}$.

Semi-quantitative RT-PCR. Total RNA extraction from tumor cells and cDNA preparation were performed as aforementioned. A volume of $1 \mu \mathrm{l}$ cDNA was used as a template for PCR analysis of Wnt10a and GAPDH expression. The Taq polymerase was supplied by Takara Biotechnology Co., Ltd. (Dalian, China) and the procedure was performed as follows: Pre-denaturation at $95^{\circ} \mathrm{C}$ for $1 \mathrm{~min}$, followed by 20 cycles of denaturation at $95^{\circ} \mathrm{C}$ for $15 \mathrm{sec}$, annealing and extension at $58^{\circ} \mathrm{C}$ for $30 \mathrm{sec}$, and hold at $72^{\circ} \mathrm{C}$ for $10 \mathrm{~min}$. The PCR products were run on a $1 \%$ agarose gel with the help of Goldview reagent (YBscience, Shanghai, China). A total of $1 \mathrm{~g}$ of agarose was added into $100 \mathrm{ml}$ TAE buffer (Sangon Biotech Co., Ltd., Shanghai, China) and boiled for $2 \mathrm{~min}$. Then $5 \mu \mathrm{l}$ of Goldview reagent was directly added into the buffer prior to becoming solid and $1 \%$ agarose gel was prepared after pouring the buffer into a module with a comber. The PCR products were added into the comber well and analyzed.

Transfection of HCT116 cells with siRNA. The sequences of Wnt10a-siRNA and negative control (NC) siRNA, which were provided by Shanghai GenePharma Co., Ltd. (Shanghai, China), are presented in Table I. Briefly, HCT116 cells were transiently transfected with Wnt10a-siRNA fragments using Lipofectamine ${ }^{\circledR}$ 2000 (Invitrogen; Thermo Fisher Scientific, Inc.), according to the manufacturer's protocol. Briefly, HCT116 cells in the exponential growth phase were seeded into 12 -well plates at a density of $1 \times 10^{4} / \mathrm{ml}$. After $24 \mathrm{~h}$, cells were transfected with $20 \mu \mathrm{mol}$ Wnt10a-siRNA by Lipofectamine ${ }^{\circledR} 2000$. After 6 h, culture medium was replaced with $500 \mu \mathrm{l}$ DMEM containing 10\% FBS. Transfected cells were cultured at $37^{\circ} \mathrm{C}$ in a humidified incubator containing $5 \% \mathrm{CO}_{2}$ before used in following functional assays.

Cell proliferation assay. Cell proliferation was evaluated by MTT assay. HCT116 cells transfected with Wnt10a-siRNA were seeded into 96 -well plates at a density of $2.5 \times 10^{3}$ cells/well in $100 \mu \mathrm{l}$ DMEM. Subsequently, $20 \mu \mathrm{l}$ MTT solution $(5 \mathrm{mg} / \mathrm{ml}$; Merck KGaA, Darmstadt, Germany) was added into each well from the 2 nd to 5 th day of incubation, for $4 \mathrm{~h}$. After removal of the supernatant, $100 \mu 1$ dimethyl sulfoxide was added to dissolve the crystals. The absorbance values (A) were measured at a wavelength of $490 \mathrm{~nm}$ with a microplate reader. Relative cell growth rate $(\mathrm{Rt})$ was calculated as follows: $\mathrm{Rt}=\mathrm{A} 490 \mathrm{~nm}\left(\right.$ Day $\left._{\mathrm{n}+1}\right) / \mathrm{A} 490 \mathrm{~nm}\left(\mathrm{Day}_{1}\right) ; \mathrm{n}=0$-4. Each experiment was performed in triplicate and repeated three times.

Wound healing assay. A total of $24 \mathrm{~h}$ following Wnt10a-siRNA transfection, a scratch was created using a plastic pipette tip, and cells were gently washed twice with PBS in order to remove the debris. Cells were then cultured in serum-free DMEM for $24 \mathrm{~h}$. At the designated time point, the distance cells had traveled in five randomly selected fields along the scratch were obtained and recorded with Nikon inverted microscope ECLIPSE TS2 (Nikon Corporation, Tokyo, Japan). The migration rate was calculated as follows: Migration rate $=\left(\mathrm{S}_{0 \mathrm{~h}}-\mathrm{S}_{24 \mathrm{~h}}\right) / \mathrm{S}_{0 \mathrm{~h}} \times 100 \%$, where $\mathrm{S}_{0 \mathrm{~h}}$ was the distance of the scratch at $0 \mathrm{~h}$ and $\mathrm{S}_{24 \mathrm{~h}}$ the distance at $24 \mathrm{~h}$. 
Table I. Primers for RT-qPCR and semi-quantitative RT-PCR and siRNA target sequence.

A, Primers for RT-qPCR

\begin{tabular}{ll}
\hline Gene & \multicolumn{1}{c}{ Sequence (5'-3') } \\
\hline Wnt10a & F-1 TGCACCGCTTACAACTGGAT \\
& R-1 TTCTCGCGTGGATGTCTCTG \\
GAPDH & F-1 GGGAGCCAAAAGGGTCATCA \\
& R-1 TGATGGCATGGACTGTGGTC \\
\hline
\end{tabular}

B, Primers for RT-PCR

\begin{tabular}{ll}
\hline Gene & \multicolumn{1}{c}{ Sequence $\left(5^{\prime}-3^{\prime}\right)$} \\
\hline Wnt10a & F-2 GAGGAGGCCTTCCGTAGGAAG \\
& R-2 ACTTCCGCCGCATGTTCTCCAT \\
GAPDH & F-2 AGGAGCGAGATCCCTCCA \\
& R-2 CCGTTCAGCTCAGGGATGAC
\end{tabular}

C, siRNA sequences

\begin{tabular}{ll} 
Gene & \multicolumn{1}{c}{ Sequence $\left(5^{\prime}-3^{\prime}\right)$} \\
\hline Wnt10a & siRNA1 GGTCAGCACCCAATGACAT \\
& siRNA2 CCACGAATGCCAACACCAA \\
Negative control & siRNA3 CCAATGACATTCTGGACCT \\
& NCGGAATGCCCTTTGAAAACCC
\end{tabular}

F, forward; R, reverse; RT-qPCR, reverse transcription-quantitative polymerase chain reaction; siRNA, small interfering RNA; Wnt10a, Wnt family member 10A.

Western blotting. Cells were cultured in 6-well plates and transfected with Wnt10a-siRNA, LGK974 alone or combined. LGK974 was purchased from Selleck Chemicals (Shanghai, China) and used at $1 \mu \mathrm{mol}$ for $36 \mathrm{~h}$ in vitro assays. Following transfection for $36 \mathrm{~h}$, total protein was extracted using iced lysis buffer (1\% Triton X-100; 50 mM Tris-HCl, pH 7.4; $150 \mathrm{mM} \mathrm{NaCl}$; $0.1 \%$ SDS; $1 \mathrm{mM}$ phenylmethanesulfonyl fluoride and $1 \mathrm{mM}$ EDTA). The protein concentration was determined with the bicinchoninic acid assay. Proteins $(10 \mu \mathrm{g})$ were separated on a $10 \%$ SDS-PAGE gel, electrotransferred onto nitrocellulose membranes followed by blocking with $5 \%$ non-fat milk at $25^{\circ} \mathrm{C}$ for $1 \mathrm{~h}$. The membranes were incubated overnight with primary mouse monoclonal antibodies against $\beta$-catenin (cat. no. sc-7963; dilution, 1:250), protein kinase B (Akt; cat. no. sc135829; dilution, 1:200), cyclin D1 (cat. no. sc70899; dilution, 1: 300, Santa Cruz Biotechnology, Inc., Dallas, TX, USA) lymphoid enhancer-binding factor 1 (LEF1, cat. no. ab215999; dilution, 1:400) and GAPDH (cat. no. ab9484; dilution, 1:200; Abcam, Cambridge, MA, USA). Membranes were then washed and incubated with horseradish peroxidase-conjugated secondary antibody (cat. no. abs20001, 1: 2,000; Absin Bioscience Inc, Shanghai, China) for $1 \mathrm{~h}$ at room temperature. Immunoreactivity was determined using an enhanced chemiluminescence kit. (cat. no. C506668; Shanghai Sangong Pharmaceutical Co., Ltd., Shanghai, China). Photoshop CS2 software (Adobe Systems, Incorporated, San Jose, CA, USA) was used to evaluate the gray value of each band and relative quantification was normalized to $\mathrm{NC}$.

Lentivirus infection. The short hairpin RNA (shRNA) targeting Wnt10a or negative control (NC) was expressed in a lentivirus vector and the lentivirus particle carrying shRNA (Wnt10a-shRNA) or NC was used to infect HCT116 cells. In brief, $5 \times 10^{6}$ HCT116 cells were treated with lentivirus at multiplicity of infection 10 for $6 \mathrm{~h}$. The supernatant was removed and fresh culture medium was added. The infection efficiency was confirmed at $72 \mathrm{~h}$ following lentivirus infection.

In vivo xenograft tumor assay. A total of $1 \times 10^{6}$ HCT116 cells infected with Wnt10a-short hairpin (sh)RNA or NC lentivirus were diluted in $100 \mu \mathrm{l}$ PBS and injected into the right flank of BALB/cASlac-nu mice (7 weeks old; 20-25 g; Shanghai SLAC Laboratory Animal Co., Ltd., Shanghai, China), housed in a specific-pathogen-free laboratory environment (12 h light/dark cycle at $25^{\circ} \mathrm{C}$ with $50 \%$ humidity and given food or water once a day). The mice were grouped into two groups (10 mice with 5 female and 5 male in each group). The tumor volume was measured once a week as follows: Length $\mathrm{x}$ width ${ }^{2} / 2$. After 5 weeks, mice were euthanized. This study was approved by The Animal Ethics Committee of The Second Affiliated Hospital of Southeast University.

Statistical analysis. All data are expressed as the means \pm standard deviation of three independent experiments, and differences between every two different groups was analyzed by one-way analysis of variance test followed Tukey's post hoc test using SPSS 16.0 (IBM Corp., Armonk, NY, USA). The association between Wnt10a expression levels and clinicopathological characteristics was analyzed by $\chi^{2}$ test. Kaplan-Meier analysis and log-rank test were used to analyze the prognosis. $\mathrm{P}<0.05$ was considered to indicate a statistically significant difference.

\section{Results}

Wntloa is upregulated in colon cancer tissues and is associated with clinicopathological factors. To analyze the expression of Wnt10a in CRC tissues, 40 pairs of tumor tissues and paratumoral tissues were collected, and total RNA was extracted. RT-qPCR analysis demonstrated that Wnt10a expression levels were significantly higher in the tumor tissues compared with in the paratumoral tissues (Fig. 1A). In addition, in $>50 \%$ of samples, Wnt10a expression levels were four times higher in tumor tissues than in paratumoral tissues, whereas the fold changes in the remaining 50\% ranged between two and four. Furthermore, Wnt10a was markedly associated with late-stage tumor $(\mathrm{T} 3+\mathrm{T} 4, \mathrm{P}=0.015)$ but not with sex $(\mathrm{P}=0.583)$, age $(\mathrm{P}=0.746)$ or distant metastasis $(\mathrm{P}=0.781)$ (Table II). In addition, Wnt10a was associated with prognosis in patients with CRC. The 5-year survival rate of patients with CRC with low Wnt10a expression levels was significantly better than in those with high Wnt10a expression (Fig. 1B). These results 
A

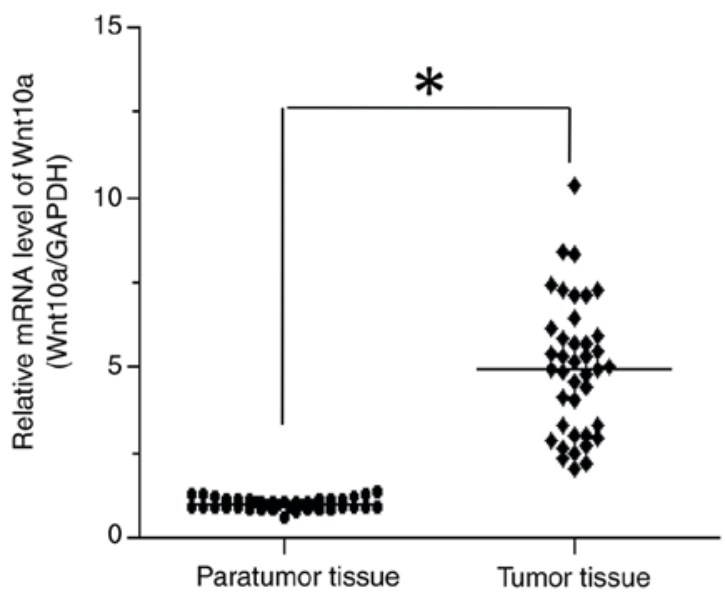

B

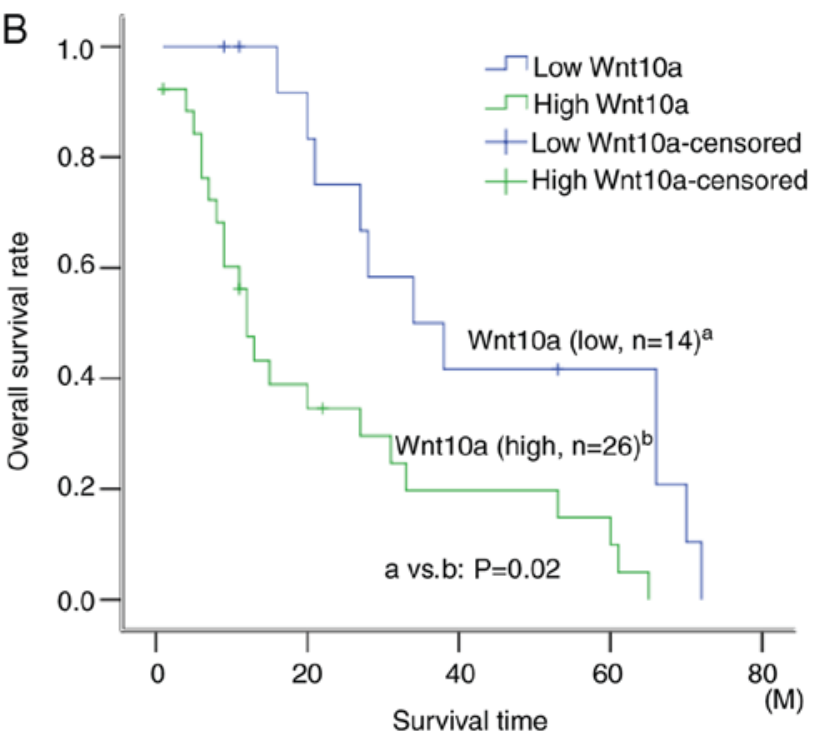

Figure 1. Expression levels of Wnt10a in colorectal tumor tissues and its clinical significance. (A) Wnt10a expression was significantly higher in the 40 tumor tissues compared with in the paired paratumoral tissues, as determined by reverse transcription-quantitative polymerase chain reaction. (B) Overall survival rate of patients with high Wnt10a expression was lower than in those with low Wnt10a expression. * $\mathrm{P}<0.05$. Wnt10a, Wnt family member $10 \mathrm{~A}$.

Table II. Association of Wnt10a expression with clinicopathological characteristics in colorectal cancer.

\begin{tabular}{lcccc}
\hline & \multicolumn{4}{c}{$\begin{array}{c}\text { Wnt10a } \\
\text { expression level }\end{array}$} \\
\cline { 3 - 4 } $\begin{array}{l}\text { Patient } \\
\text { characteristics }\end{array}$ & Total & $\leq 4$ folds & $>4$ folds & P-value \\
\hline $\begin{array}{l}\text { All cases } \\
\text { Age (years) }\end{array}$ & 40 & 12 & 28 & \\
$\leq 60$ & 13 & 6 & 7 & 0.746 \\
$>60$ & 27 & 11 & 16 & \\
TNM stage & & & & 0.015 \\
T1+T2 & 16 & 9 & 7 & \\
T3+T4 & 24 & 4 & 20 & \\
Sex & & & & 0.583 \\
Male & 21 & 16 & 5 & \\
Female & 19 & 13 & 6 & \\
Distant metastasis & & & & 0.781 \\
Yes & 18 & 13 & 5 & \\
No & 22 & 15 & 7 & \\
\hline
\end{tabular}

suggested that elevated expression levels of Wnt10a may be associated with the carcinogenesis and progression of CRC.

Knockdown of Wnt10a suppresses proliferation of HCT116 cells. In the present study, RT-qPCR analysis revealed that Wnt10a was expressed in the three CRC cell lines SW480, SW620 and HCT116, which suggested that Wnt10a may contribute to CRC cell proliferation (Fig. 2A).

In order to explore the role of Wnt10a in HCT116 cells, a loss of function assay was designed, and three siRNA fragments targeting the Wnt10a coding sequence were synthesized and transfected into HCT116 cells. After 48 h transfection,
RT-qPCR analysis demonstrated that the expression levels of Wnt10a in transfected HCT116 cells were significantly decreased (Fig. 2B). These results indicated that Wnt10a was efficiently knocked down in HCT116 cells. An MTT assay was then performed to analyze the growth ability of HCT116 cells following Wnt10a-siRNA transfection. As shown in Fig. 2C, the growth of Wnt10a-siRNA-transfected HCT116 cells was significantly decreased compared with in the NC group. Furthermore, cell growth was slower in Wnt10a-siRNA1-transfected HCT116 cells, indicating that transfection with siRNA1 was the most efficient. Wnt10a-siRNA1 was therefore used in subsequent experiments. These data demonstrated that Wnt10a may have a positive effect on HCT116 cell growth.

Wnt10a knockdown suppresses migration of HCT116 cells. In addition to unlimited proliferation, migration and invasion are other hallmarks of tumor cells $(19,22,23)$. The migratory ability of HCT116 cells transfected with Wnt10a-siRNA1 was assessed with the wound healing assay. As shown in Fig. 3A, the migratory ability of Wnt10a-siRNA1-transfected HCT116 cells were significantly disrupted compared with the NC group. The migrated distance in Wnt10a-siRNA1-transfected HCT116 cells was shorter than that in the NC group. The migration rate of HCT116 cells transfected with Wnt10a-siRNA1 was $\sim 24.3 \%$, whereas it was $\sim 50 \%$ in the NC group. This demonstrated that the motility of HCT116 cells was markedly decreased post-transfection with siRNA1 (Fig. 3B). These data suggested that Wnt10a may stimulate HCT116 cell migration. In addition, Wnt10a downregulation suppressed the proliferation and migration of HCT116 cells. Since Wnt10a was overexpressed in CRC tissues, this suggested that Wnt10a may have an oncogenic role in CRC.

Wnt10a is essential to growth of xenograft tumor in vivo. As aforementioned, Wnt10a may be important for the proliferation and migration of HCT116 cells in vitro. Wnt10a knockdown may also inhibit HCT116 cell growth in vivo. The results of 

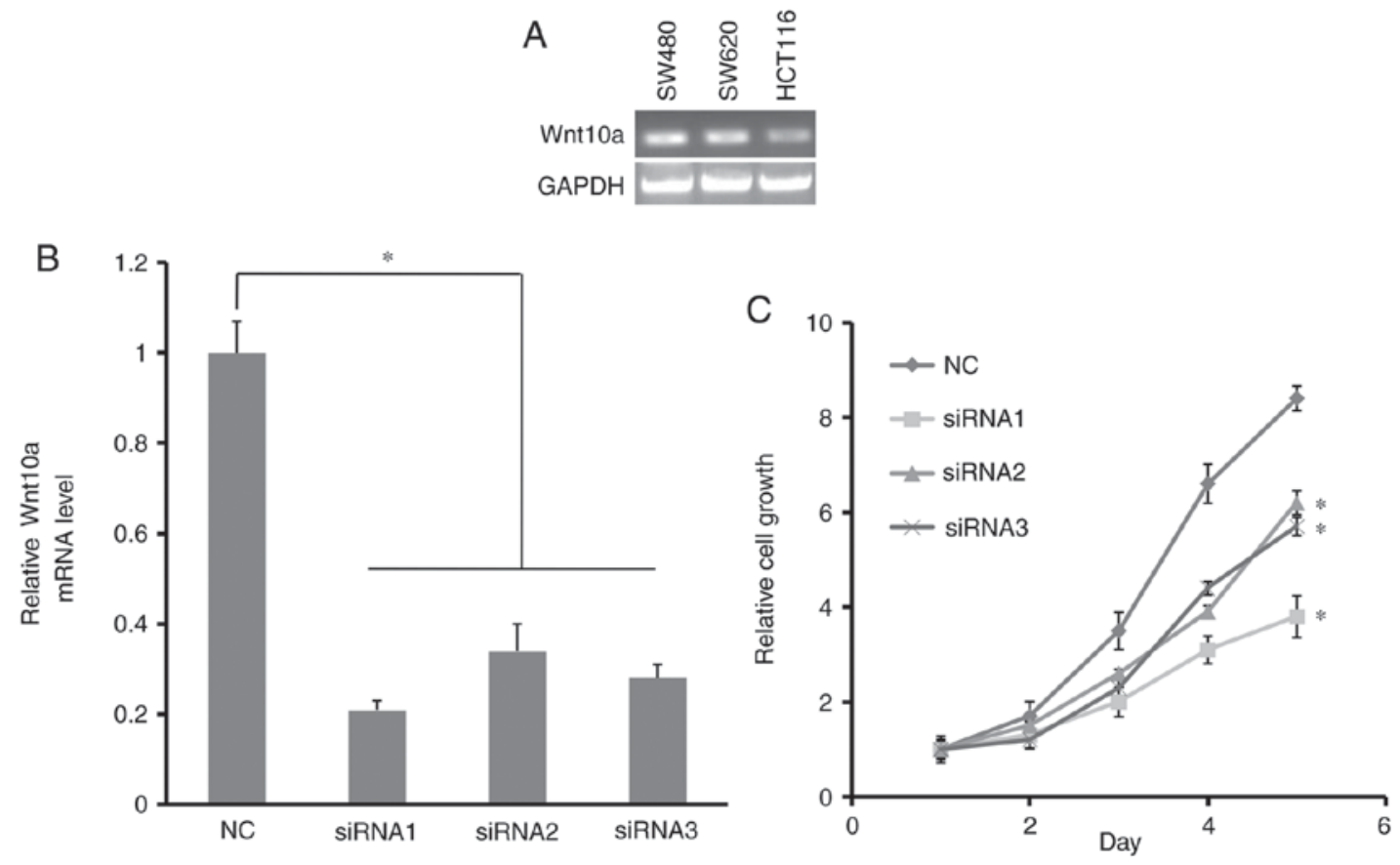

Figure 2. Effects of Wnt10a knockdown on HCT116 cell proliferation. (A) Expression levels of Wnt10a in three CRC cell lines: SW480, SW620 and HCT116. (B) Knockdown efficiency of Wnt10a in HCT116 cells assessed by reverse transcription-quantitative polymerase chain reaction. (C) Growth curve analysis of HCT116 cells transfected with Wnt10a-siRNA. " $\mathrm{P}<0.05$. All data were obtained from triplicate experiments. NC, negative control; siRNA, small interfering RNA; Wnt10a, Wnt family member 10A.

A
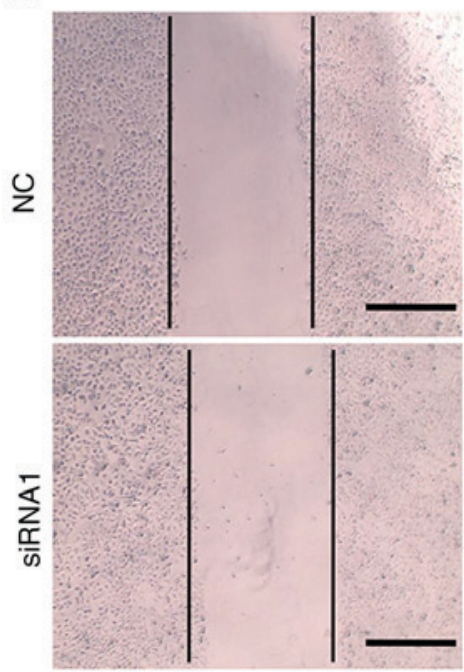

$24 \mathrm{~h}$

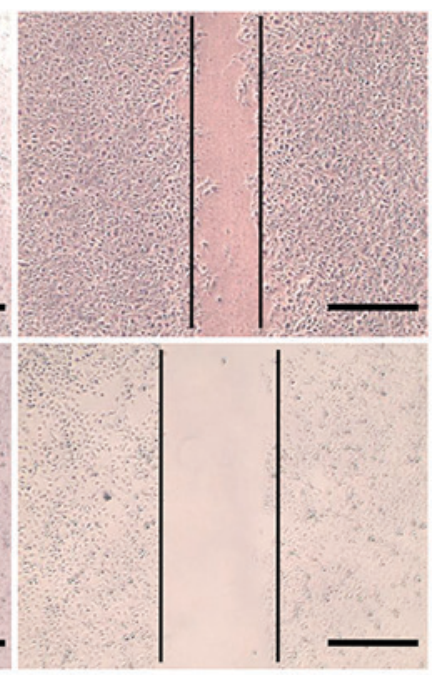

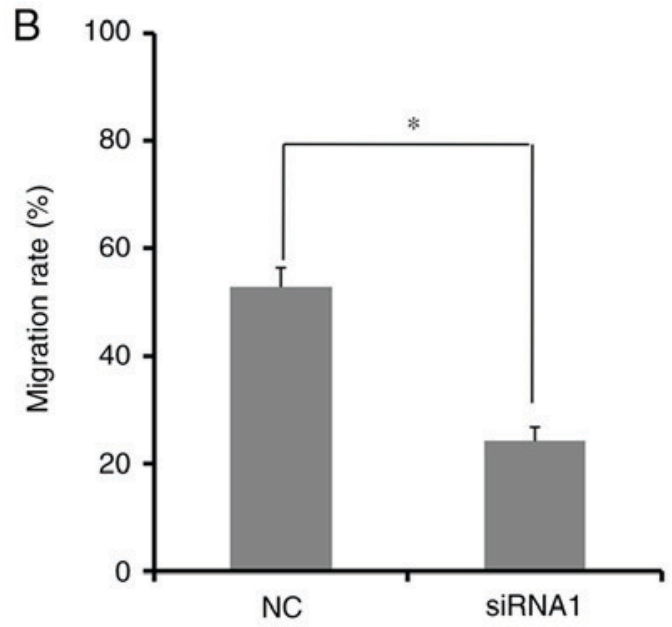

Figure 3. Effects of Wnt10a knockdown on HCT116 cell migration. (A) Migrated distance of HCT116 cells transfected with Wnt10a-siRNA1 within 24 h, as determined using the wound healing assay. Magnification, x20. (B) Migration rate calculated from the wound healing assay. "P<0.05. All data were obtained from triplicate experiments. NC, negative control; siRNA, small interfering RNA; Wnt10a, Wnt family member 10A.

the xenograft assay demonstrated that HCT116 xenograft tumor growth was significantly reduced when HCT116 cells underwent Wnt10a knockdown. As shown in Fig. 4A, prior to cell implantation in mice, the expression levels of Wnt10a were decreased by $\sim 38 \%$ by Wnt10a-shRNA. The tumor volume was $\sim 1,430 \mathrm{~mm}^{3}$ in the control group, whereas it was $\sim 680 \mathrm{~mm}^{3}$ in the Wnt10a knockdown mice on day 35 (Fig. 4B). The in vivo data was therefore consistent with the in vitro results; further supporting that Wnt10a may have an oncogenic role in CRC.
Wnt10a activates Wnt/ $\beta$-catenin signaling in HCT116 cells. A previous study reported that Wnt10a activates the canonical Wnt/ $\beta$-catenin signaling pathway in RCC cells (19). In the present study, the activity of Wnt/ $\beta$-catenin signaling in HCT116 cells was therefore determined following Wnt10a-siRNA transfection. Western blotting revealed that the expression levels of $\beta$-catenin, cyclin D1, LEF1 and Akt were markedly decreased in the Wnt10a-siRNA1-transfected HCT116 cells and the LGK-974-treated HCT116 cells compared with the control (Fig. 5A and B). LGK-974 is a specific inhibitor 

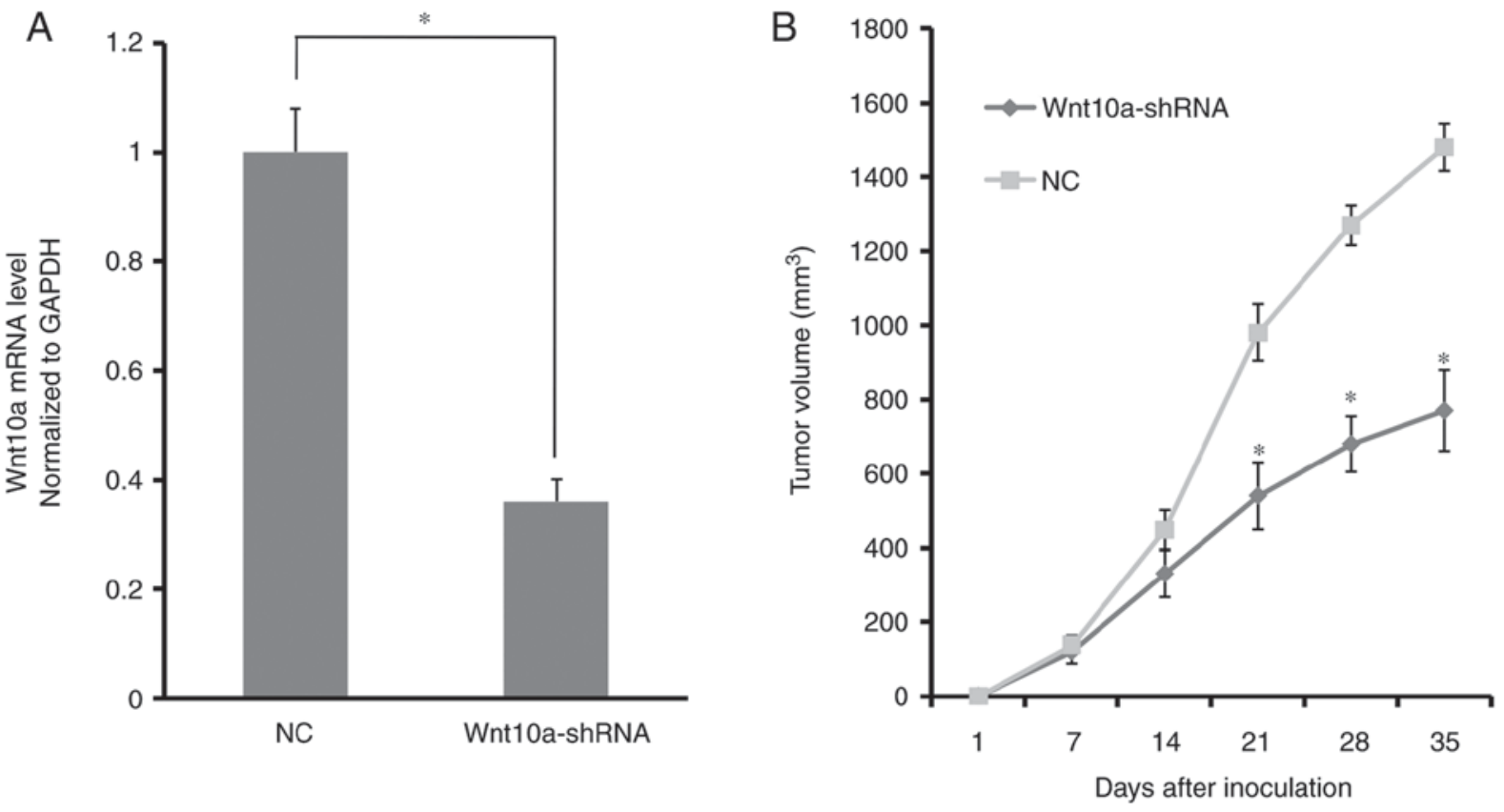

Figure 4. Wnt10A knockdown suppresses tumor growth in vivo. (A) Expression levels of Wnt10a were decreased by Wnt10a-shRNA. (B) Tumor growth was delayed in mice treated with Wnt10a-shRNA. "P<0.05. NC, negative control; shRNA, short hairpin RNA; Wnt10a, Wnt family member 10A.

that targets the Porcupine protein and blocks canonical Wnt/ $\beta$-catenin signaling. The present results also suggested that there was no synergistic effect between Wnt10a-siRNA and LGK-974 on the proliferation of HCT116 cells, as minimal proliferative differences were observed between groups treated with Wnt10a-siRNA and LGK-974 alone, and their combination (Fig. 5C). Therefore, Wnt10a may promote HCT116 cell growth via $\mathrm{Wnt} / \beta$-catenin signaling.

\section{Discussion}

Wnt signaling is essential during embryonic development and pathological processes, particularly in cancer. Wnt10a, one member of the Wnt family, is normally abundant in the fetal kidney, placenta, and adult spleen and kidney. It is also abnormally overexpressed in the SW480 CRC cell line $(20,21)$. In the present study, Wnt10a was strongly expressed in HCT116 cells. In addition, to the best of our knowledge, this is the first study to demonstrate that Wnt10 expression levels were overexpressed in colorectal tumor tissues compared with in paratumoral tissues. Wnt10a expression levels were also positively associated with late tumor stage. Furthermore, high Wnt10a expression was associated with a poor 5-year survival rate in patients with CRC. These results suggested that Wnt10a may serve important roles in the initiation and/or progression of CRC.

Tumor cells are characterized by unlimited cell proliferation and resistance to the immune system (24). Aggressiveness is another hallmark of tumors and can lead to metastasis in patients with cancer $(19,24,25)$. Previous studies have reported that Wnt10a is highly expressed in SW480 cells (20), and that it promotes proliferation and invasion of renal cancer cells (19). In the present study, Wnt10a was demonstrated to be critical to the growth and invasiveness of CRC cells. Furthermore, the study revealed that Wnt10a knockdown in HCT116 cells significantly inhibited xenograft colorectal tumor growth in vivo. To the best of our knowledge, the present study was the first to report a role for Wnt10a in CRC in vivo. These results suggested that Wnt10a may have an oncogenic role in CRC tumorigenesis, in vitro and in vivo.

Wnt10a has been demonstrated to activate the canonical Wnt/ $\beta$-catenin signaling pathway in RCC cells (19). In the present study, Wnt10a also contributed to activation of Wnt/ $\beta$-catenin signaling in CRC. As previously stated, the expression levels of critical downstream molecules, including $\beta$-catenin, cyclin D1 and LEF1, were decreased in Wnt10a-siRNA-transfected HCT116 cells. TCF/LEF1 is the main effector of the Wnt signaling pathway and is increased in various types of tumor (26). Furthermore, Akt was downregulated in Wnt10a-siRNA HCT116 cells. Akt is the central component of the phosphoinositide 3-kinase/Akt/mammalian target of rapamycin (mTOR) signaling cascade, which regulates cell proliferation and survival (27). These results were similar to those obtained following cell treatment with LGK-974. In addition, no synergistic effect on HCT116 cell proliferation was observed between Wnt10a-siRNA and LGK-974. Wnt10a may therefore partly promote HCT116 cell growth by regulating Wnt/ $\beta$-catenin signaling.

Previous studies have revealed that tumor metabolism is important for cancer progression $(8,28)$. The Akt-mTOR signaling pathway enhances aerobic glycolysis in cancer cells and supports de novo macromolecular synthesis by regulating nutrient uptake and carbon/nitrogen allocation $(29,30)$. The present study revealed that Akt expression was downregulated in Wnt10a-siRNA-transfected HCT116 cells. Wnt10a may thus promote tumor growth partly by regulating tumor metabolism in patients with CRC. In addition, other members of the Wnt family have been reported to be involved in carcinogenesis and/or progression of CRC, leading to the development of specific inhibitors of Wnt (31-33). The association between Wnt10a and other Wnt molecules in CRC requires further 

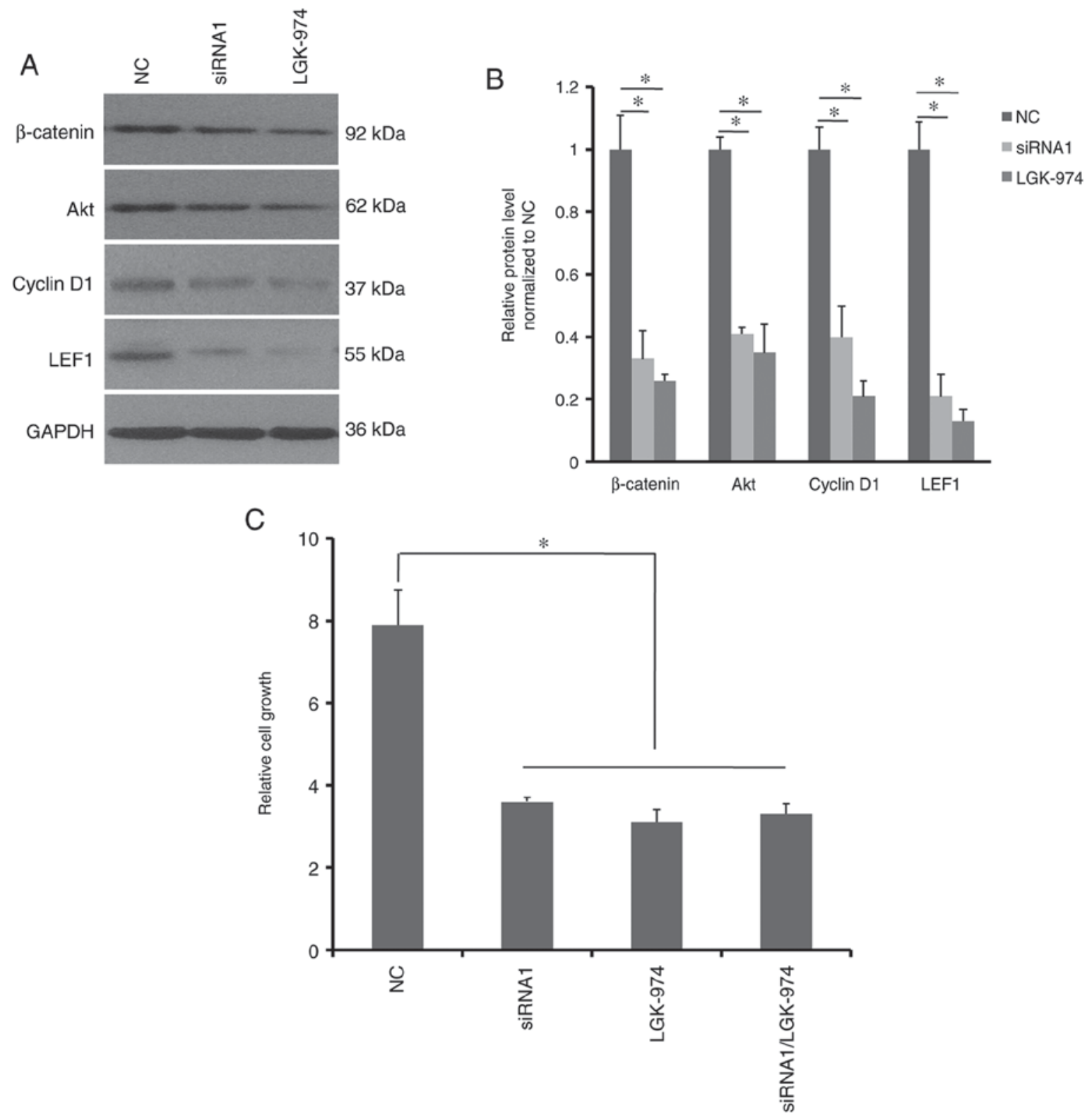

Figure 5. Wnt10a knockdown inactivates the Wnt/3-catenin signaling pathway. (A and B) Both Wnt10a-siRNA and LGK-974 inhibitor decreased the expression of $\beta$-catenin, Akt, cyclin D1 and LEF1 in HCT116 cells. (C) Effect of Wnt10a-siRNA and LGK-974 on HCT116 cell growth at $48 \mathrm{~h}$ following treatment with Wnt10a-siRNA or LGK-974. Relative proliferation rate was normalized to the cells at $0 \mathrm{~h}$ timepoint. "P<0.05. Akt, protein kinase B; LEF1, lymphoid enhancer-binding factor 1; NC, negative control; siRNA, small interfering RNA; Wnt10a, Wnt family member 10A.

investigation. Furthermore, clinical data of samples from a larger cohort of patients with CRC is necessary to evaluate the role of Wnt10a in survival and prognosis in patients with CRC.

In conclusion, the present study demonstrated that Wnt10a may have an oncogenic role during carcinogenesis and progression of $\mathrm{CRC}$, suggesting that Wnt10a may represent a potential novel target for the treatment of patients with CRC.

\section{Acknowledgements}

Not applicable.

\section{Funding}

This work was supported by the National Natural Science Foundation of China (grant no. 81703088).

\section{Availability of data and materials}

The datasets used and/or analyzed during the current study are available from the corresponding author on reasonable request.

\section{Authors' contributions}

JL and YZ designed the study. JL carried out the major experiments and wrote the manuscript. YZ reviewed the manuscript. $\mathrm{ZZ}$ and LW analyzed and interpreted the data, and the literature study. All authors read and approved the final version of the manuscript.

\section{Ethics approval and consent to participate}

The animal study was approved by the Institutional Review Board of the Second Affiliated Hospital of Southeast 
University. The study using human samples was approved by the Ethics Committee of The Second Affiliated Hospital of Southeast University (Nanjing, China). Written informed consent form was obtained from all patients.

\section{Patient consent for publication}

The patients provided written informed consent for the publication of any associated data.

\section{Competing interests}

The authors declare that they have no competing interests.

\section{References}

1. Siegel RL, Miller KD, Fedewa SA, Ahnen DJ, Meester RGS, Barzi A and Jemal A: Colorectal cancer statistics, 2017. CA Cancer J Clin 67: 177-193, 2017.

2. Pabla B, Bissonnette M and Konda VJ: Colon cancer and the epidermal growth factor receptor: Current treatment paradigms, the importance of diet and the role of chemoprevention. World J Clin Oncol 6: 133-141, 2015.

3. Millan M, Merino S, Caro A, Feliu F, Escuder J and Francesch T: Treatment of colorectal cancer in the elderly. World J Gastrointest Oncol 7: 204-220, 2015.

4. Applegate CC and Lane MA: Role of retinoids in the prevention and treatment of colorectal cancer. World J Gastrointest Oncol 7 : 184-203, 2015.

5. Yan Y and Grothey A: Molecular profiling in the treatment of colorectal cancer: Focus on regorafenib. Onco Targets Ther 8: 2949-2957, 2015

6. Woo IS and Jung YH: Metronomic chemotherapy in metastatic colorectal cancer. Cancer Lett 400: 319-324, 2017.

7. Barranha R, Costa JL, Carneiro F and Machado JC: Genetic Heterogeneity in colorectal cancer and its clinical implications Acta Med Port 28: 370-375, 2015.

8. Sherwood V: WNT signaling: An emerging mediator of cancer cell metabolism? Mol Cell Biol 35: 2-10, 2015.

9. Hashimoto T, Yamashita S, Yoshida H, Taniguchi H, Ushijima T, Yamada T, Saito Y, Ochiai A, Sekine S and Hiraoka N: WNT pathway gene mutations are associated with the presence of dysplasia in colorectal sessile serrated adenoma/polyps. Am J Surg Pathol 41: 1188-1197, 2017.

10. Men XM, Deng B, Tao X, Qi KK and Xu ZW: Wnt gene expression in adult porcine longissimus dorsi and its association with muscle fiber type, energy metabolism, and meat quality. J Integr Agr 16: 144-150, 2017.

11. Clevers $\mathrm{H}$ : Wnt/beta-catenin signaling in development and disease. Cell 127: 469-480, 2016.

12. Nusse $R$ and Clevers $H$ : Wnt $/ \beta$-catenin signaling, disease and emerging therapeutic modalities. Cell 169: 985-999, 2017.

13. Mccracken KW, Aihara E, Martin B, Crawford CM, Broda T, Treguier J, Zhang X, Shannon JM, Montrose MH and Wells JM: $\mathrm{Wnt} / \beta$-catenin promotes gastric fundus specification in mice and humans. Nature 541: 182-187, 2017.

14. Arend RC,Londoño-Joshi AI, Straughn JM Jr and Buchsbaum DJ: The Wnt/ $\beta$-catenin pathway in ovarian cancer: A review. Gynecol Oncol 131: 772-779, 2013

15. Stanczak A, Stec R, Bodnar L, Olszewski W, Cichowicz M, Kozlowski W, Szczylik C, Pietrucha T, Wieczorek M and Lamparska-Przybysz M: Prognostic significance of Wnt-1, $\beta$-catenin and E-cadherin expression in advanced colorectal carcinoma. Pathol Oncol Res 17: 955-963, 2011.
16. Yoshioka S, King ML, Ran S, Okuda H, MacLean JA II, McAsey ME, Sugino N, Brard L, Watabe K and Hayashi K: WNT7A regulates tumor growth and progression in ovarian cancer through the WNT/ $\beta$-catenin pathway. Mol Cancer Res 10: 469-482, 2012

17. BakkerER,Das AM,Helvensteijn W, Franken PF, Swagemakers S, van der Valk MA, ten Hagen TL, Kuipers EJ, van Veelen W and Smits R: Wnt5a promotes human colon cancer cell migration and invasion but does not augment intestinal tumorigenesis in Apc1638N mice. Carcinogenesis 34: 2629-2638, 2013.

18. Galbraith RL, Poole EM, Duggan D, Muehling J,Hsu L, Makar K, Xiao L, Potter JD and Ulrich CM: Polymorphisms in WNT6 and WNT10A and colorectal adenoma risk. Nutr Cancer 63: 558-564, 2011.

19. Hsu RJ, Ho JY, Cha TL, Yu DS, Wu CL, Huang WP, Chu P, Chen YH, Chen JT and Yu CP: WNT10A plays an oncogenic role in renal cell carcinoma by activating WNT/beta-catenin pathway. PLoS One 7: e47649, 2012.

20. Kirikoshi H, Inoue S, Sekihara $\mathrm{H}$ and Katoh M: Expression of WNT10A in human cancer. Int J Oncol 19: 997-1001, 2011.

21. Kirikoshi H, Sekihara H and Katoh M: WNT10A and WNT6, clustered in human chromosome $2 \mathrm{q} 35$ region with head-to-tail manner, are strongly coexpressed in SW480 cells. Biochem Biophys Res Commun 283: 798-805, 2001.

22. Cunninghan D, Atkin W, Lenz HJ, Lynch HT, Minsky B, Nordlinger B and Starling N: Colorectal cancer. Lancet 375 : 1030-1047, 2010

23. Livak KJ and Schmittgen TD: Analysis of relative gene expression data using real-time quantitative PCR and the 2(-Delta Delta C (T)) method. Methods 25: 402-408, 2001.

24. Hanahan D and Weinberg R: Hallmarks of cancer: The next generation. Cell 144: 646-674, 2011.

25. März L and Piso P: Treatment of peritoneal metastases from colorectal cancer. Gastroenterol Rep 3: 298-302, 2015.

26. Hrckulak D, Kolar M, Strnad H and Korinek V: TCF/LEF transcription factors: An update from the internet resources. Cancer (Basel) 8: pii: E70, 2016.

27. Yu JS and Cui W: Proliferation, survival and metabolism: The role of PI3K/AKT/mTOR signaling in pluripotency and cell fate determination. Development 143: 3050-3060, 2016.

28. Kimmelman AC and White E: Autophagy and tumor metabolism. Cell Metab 25: 1037-1043, 2017.

29. Zoncu R, Efeyan A and Sabatini DM: mTOR: From growth signal integration to cancer, diabetes and ageing. Nat Rev Mol Cell Biol 12: 21-35, 2011.

30. Bahrami A, Hasanzadeh M, Hassanian SM, ShahidSales S, Ghayour-Mobarhan M, Ferns GA and Avan A: The potential value of the PI3K/Akt/mTOR signaling pathway for assessing prognosis in cervical cancer and as a target for therapy. J Cell Biochem 118: 4163-4169, 2017.

31. Yoshida N, Kinugasa T, Ohshima K, Yuge K, Ohchi T, Fujino S, Shiraiwa S, Katagiri M and Akagi Y: Analysis of Wnt and b-catenin expression in advanced colorectal cancer. Anticancer Res 35: 4403-4410, 2015.

32. Zhang $X$ and Hao J: Development of anticancer agents targeting the Wnt/ $\beta$-catenin signaling. Am J Cancer Res 5: 2344-2360, 2015.

33. Tran FH and Zheng JJ: Modulating the wnt signaling pathway with small molecules. Protein Sci 26: 650-661, 2017.

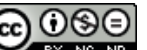

This work is licensed under a Creative Commons Attribution-NonCommercial-NoDerivatives 4.0 International (CC BY-NC-ND 4.0) License. 